\title{
Hot Deformation Behaviour and Processing Map of Cast Alloy 825
}

\author{
Munir Al-Saadi, Christopher Hulme-Smith (D), Fredrik Sandberg, and Pär G. Jönsson
}

\author{
Submitted: 8 March 2021 / Revised: 7 May 2021 / Accepted: 31 May 2021 / Published online: 22 June 2021
}

\begin{abstract}
Alloy 825 is a nickel-based alloy that is commonly used in applications where both high strength and corrosion resistance are required, such as tanks in the chemical, food and petrochemical industries and oil and gas pipelines. Components made from Alloy 825 are often manufactured using hot deformation. However, there is no systematic study to optimise the processing conditions reported in literature. In this study, a processing map for as-cast Alloy 825 is established to maximise the power dissipation efficiency of hot deformation in the temperature range of 950 to 1250 ${ }^{\circ} \mathrm{C}$ at an interval of $50{ }^{\circ} \mathrm{C}$ and strain rate range of $0.01 \mathrm{~s}^{-1}$ to $10.0 \mathrm{~s}^{-1}$ to a true strain of 0.7 using a Gleeble-3500 thermomechanical simulator. The processing conditions are also correlated to the Vickers hardness of the final material, which is also characterised using optical microscopy and scanning electron microscopy, including electron backscattered diffraction. The true stress-true strain curves exhibit peak stresses followed by softening due to occurrence of dynamic recrystallization. The activation energy for plastic flow in the temperature range tested is approximately $450 \mathrm{~kJ} \mathrm{~mol}^{-1}$, and the value of the stress exponent in the (hyperbolic sine-based) constitutive equation, $n=5.0$, suggests that the rate-limiting mechanism of deformation is dislocation climb. Increasing deformation temperature led to a lower Vickers hardness in the deformed material, due to increased dynamic recrystallization. Raising the strain rate led to an increase in Vickers hardness in the deformed material due to increased work hardening. The maximum power dissipation efficiency is over $35 \%$, obtained for deformation in the temperature range $1100-1250{ }^{\circ} \mathrm{C}$ and a strain rate of $0.01 \mathrm{~s}^{-1}-0.1 \mathrm{~s}^{-1}$. These are the optimum conditions for hot working.
\end{abstract}

Keywords alloy 825, activation energy, dynamically recrystallized, grain size, hot deformation, stress-strain curve

\section{Introduction}

Alloy 825 is a solid solution hardening nickel-based alloy (Ref 1) that is used widely in various applications at elevated temperatures under high stress and in corrosive environments, such as tanks in the chemical and oil and gas industries, agitators and heat-exchanger systems (Ref 1,2). The mechanical and electrochemical properties of the alloy depend on the final grain size. During hot working of nickel-based superalloys and other austenitic alloys, the dominant metallurgical phenomenon is usually dynamic recrystallization, which counteracts the strain hardening caused by the mechanical working of the material and leads to grain refinement (Ref 3-5). However, dynamic recovery also occurs and reduces dislocation density, in competition with recrystallization, without refining grain size. Recrystallization can be detected due to an increase in the

Munir Al-Saadi, R\&D Metallurgy, AB Sandvik Materials Technology, SE-811 81 Sandviken, Sweden; and Department of Materials Science and Engineering, KTH Royal Institute of Technology, Brinellvägen 23, SE-100 44 Stockholm, Sweden; Christopher Hulme-Smith and Pär G. Jönsson, Department of Materials Science and Engineering, KTH Royal Institute of Technology, Brinellvägen 23, SE-100 44 Stockholm, Sweden; and and Fredrik Sandberg, R\&D Metallurgy, AB Sandvik Materials Technology, SE-811 81 Sandviken, Sweden. Contact e-mails: munir.alsaadi@sandvik.com,muniras@kth.se, and chrihs@kth.se.

\begin{tabular}{|c|c|}
\hline \multicolumn{2}{|r|}{ Abbreviations } \\
\hline \multicolumn{2}{|c|}{ Symbol Description } \\
\hline$\Sigma$ & A coincidence site lattice value \\
\hline$\sigma_{\mathrm{c}}$ & A critical stress, $\mathrm{MPa}$ \\
\hline$\varepsilon_{\mathrm{c}}$ & A critical strain \\
\hline$\theta$ & The strain hardening rate, $\mathrm{MPa}$ \\
\hline$\sigma_{\mathrm{p}}$ & Peak stress, MPa \\
\hline$\varepsilon_{\mathrm{p}}$ & Peak strain \\
\hline $\mathrm{Z}$ & Zener-Hollomon parameter, $\mathrm{s}^{-1}$ \\
\hline DDM & Dynamic Materials Modelling \\
\hline$P$ & $\begin{array}{l}\text { A total deformation power applied to the } \\
\text { material, Joule }\end{array}$ \\
\hline$G$ & Power dissipation into plastic flow, Joule \\
\hline$J$ & $\begin{array}{l}\text { Power dissipation into metallurgical } \\
\text { phenomena }\end{array}$ \\
\hline$\eta$ & $\begin{array}{l}\text { The parameter of the efficiency of power } \\
\text { dissipation, } \%\end{array}$ \\
\hline$\xi$ & Metallurgical instability during plastic flow \\
\hline$a, b$, and $c$ & $\begin{array}{l}\text { Temperature-dependent strength } \\
\text { parameters }\end{array}$ \\
\hline$\sigma$ & True stress, MPa \\
\hline$\dot{\varepsilon}$ & Strain rate, $\mathrm{s}^{-1}$ \\
\hline$T$ & Deformation temperature, $\mathrm{K}$ \\
\hline$R$ & $\begin{array}{l}\text { The universal gas constant, } \\
8.314 \mathrm{~J} \mathrm{~mol}^{-1} \mathrm{~K}^{-1}\end{array}$ \\
\hline$Q_{\sinh }$ & $\begin{array}{l}\text { The apparent activation energy for } \\
\text { deformation, } \mathrm{J} \mathrm{mol}^{-1}\end{array}$ \\
\hline$A A^{\prime}, n, \beta, n^{\prime}$, and & Material constants \\
\hline$\alpha$ & Strain rate sensitivity \\
\hline EBSD & Electron Backscattered Diffraction \\
\hline OIM & Orientation imaging microscopy \\
\hline GOS & Grain Orientation Spread, ${ }^{\circ}$ \\
\hline PSN & Particle Stimulated Nucleation \\
\hline
\end{tabular}


prevalence of high-angle grain boundaries (Ref 6, 7), twin boundaries (Ref 6) and boundaries with high coincidence (e.g. a coincidence site lattice value, $\Sigma$, of $3,5,7$, etc., which form through recrystallization (Ref 8 ). Creep and adiabatic heating through lattice friction also affect the response of the material during hot working (Ref 9). All of these processes are dependent on the deformation temperature and can be represented as a function of both temperature and processing parameters. It is important to understand the relative influences of each mechanism to achieve careful control of the hot working process (Ref 10-12). This will make it possible to achieve a homogeneous microstructure without regions of porosity. Pores lead to a loss of corrosion resistance, and so, preventing the formation of pores will ensure corrosion resistance throughout the material (Ref 13). The focus of this study is to explore process conditions under which a homogeneous microstructure can be achieved from typical continuously cast feedstock during hot forging processes that are used in industry to manufacture components from alloy 825 . This complements existing studies on similar (but not identical) alloys (Ref 13).

Dynamic recrystallization is also the most important softening mechanism during the hot deformation of austenitic stainless steels (Ref 14-22). It leads to the formation of fine grains and therefore affects the mechanical properties of the deformed material (Ref 6). Dynamic recrystallization is triggered at a critical stress, $\sigma_{\mathrm{c}}$ and critical strain, $\varepsilon_{\mathrm{c}}(\operatorname{Ref} 23,24)$ or (equivalently) above a critical dislocation density (Ref 25 , 26). After dynamic recrystallization begins, the material starts to soften, and this eventually negates strain hardening, at which point the strain hardening rate, $\frac{d \sigma}{d \varepsilon}=\theta$, becomes zero. The microstructure at this stage is called a "necklace" structure (Ref 19, 27). The corresponding stress and strain are known as peak stress, $\sigma_{\mathrm{p}}$ and peak strain, $\varepsilon_{\mathrm{p}}(\operatorname{Ref} 6,23,24,28)$. It is possible to find the values of peak and critical stress and strain from experimental stress-strain data (Ref 24, 29). Since dynamic recrystallization is time- and temperature-dependent, it should be possible to relate the peak stress and strain to the temperature and deformation strain rate. These parameters are represented in the Zener-Hollomon parameter, $Z$. The reader is referred to existing literature for a justification of the definitions of each measured quantity $\left(\sigma_{\mathrm{c}}, \sigma_{\mathrm{c}}, \theta, \sigma_{\mathrm{p}}\right.$ and $\left.\varepsilon_{\mathrm{p}}\right)(\operatorname{Ref} 30)$.

The correlation between the final microstructure and mechanical properties are altered by the workability of steels and alloys through the deformation conditions such as the deformation temperature, strain rate and total strain, applied during the hot-forming process. The hot working behaviour of Ni-based alloy systems has been studied extensively for a wide range of processing conditions (Ref 3, 31-45). Constitutive modelling has aided in establishing these relationships, connecting the various parameters (Ref 27-30).

Deformation maps have been derived to identify suitable conditions for processing particular materials, while avoiding areas prone to cracking or other failure (Ref 9, 38, $43,46,47)$. Further advances in continuum mechanics and constitutive relationships between various parameters have led to the concept of dynamic materials modelling (DMM) (Ref 32, 48-51). The total power absorbed by the material during plastic deformation can be considered in two parts: the power dissipated to perform plastic flow, $G$, and the power used to drive metallurgical phenomena, such as dynamic recovery, void formation, fracture or internal cracking or dissolution of secondary phases, $J . J$ can thus be understood as framework to capture dynamic events based on thermodynamic and mechanistic models. Dynamic materials modelling has been used to model the processing conditions for Ni-based alloys (Ref 2, 29-43). Previous investigations on Alloy 825 were focused mainly on $\mathrm{Cr}_{23} \mathrm{C}_{6}$ precipitation (Ref 52, 53) and quantifying corrosion resistance (Ref $2,54,55)$, while the study of hot deformation behaviour has received relatively little attention (Ref 13, 56, 57). The present work analyses the dependence of flow behaviour on strain rate and temperature. From this, a processing map based on dynamic materials modelling is developed (Ref 50,58). With such a map, it would be possible to find the optimum hot working processing windows for Alloy 825 and optimise the microstructure in the hot-worked material.

\subsection{Establishment of Constitutive Equation (Kinetic Analysis)}

The relation between the true stress $(\sigma)$, strain rate $(\dot{\varepsilon})$ and deformation temperature $(T)$ can be given by equating a constitutive hyperbolic-sine-type equation incorporating stress and the Zener-Hollomon parameter, $Z$, an Arrhenius-type expression incorporating strain rate and temperature (Ref 11, 59-66) (Eq 1, where $A, n$ and $\alpha$ are material constants that vary with stress, $R$ is the universal gas constant, $8.314 \mathrm{~J} \mathrm{~mol}^{-1} \mathrm{~K}^{-1}, T$ is the absolute temperature, $Q_{\sinh }$ is the apparent activation energy for deformation, $\dot{\varepsilon}$ is the strain rate, and $\sigma$ is the peak true stress).

$Z_{\mathrm{sinh}}=\dot{\varepsilon} \exp \left(Q_{\sinh } / R T\right)=A[\sinh (\alpha \sigma)]^{n}$

When the argument of the hyperbolic sine function is small, the function approximates to the argument itself (Eq 2, where $e^{x} \rightarrow$ $(1+x)$ when $x \rightarrow 0$ and so $\sinh x \approx x)$. Conversely, at large arguments, the function tends to a simple positive exponential (Eq 2, where $e^{-x} \rightarrow 0$ when $x$ is large and so $\sinh x \approx \frac{1}{2} e^{x}$ ). Therefore, when $\alpha \sigma<0.8, Z$ can be expressed as a power law (Eq 3, where $A^{\prime}=A \alpha^{n^{\prime}}$ and the use of the prime symbol $\left(^{\prime}\right.$ ) indicates that each variable relates to this approximate expression and not (1). Taking the natural logarithm of (3 allows the derivation of the unknown materials parameters, $A^{\prime}$ and $n^{\prime}$ from the flow curves (Eq 4).

$\sinh x=\frac{1}{2}\left(e^{x}-e^{-x}\right)$

$Z_{\mathrm{P}}=\dot{\varepsilon} \exp \left(Q_{\mathrm{p}} / R T\right)=A^{\prime} \sigma^{n^{\prime}}$

$\ln \varepsilon=\left(\frac{-Q_{p}}{R T}\right)+\ln A^{\prime}+n^{\prime} \ln \sigma$

When $\alpha \sigma>1.2, Z$ can be approximated by an exponential function (Eq 5, where the double prime (") symbols indicate that the values are associated with the exponential form of the function and not $\mathrm{Eq} 1$ or 3). Taking logarithms allows the variables $A^{\prime \prime}$ and $\beta=\alpha n^{\prime \prime}$ to be derived from flow data (Eq 6).

Taking natural logarithm from each side of Eq 5 yields Eq 6 , which can be used to extract the unknown material constant $\beta$.

$Z_{\mathrm{E}}=\dot{\varepsilon} \exp \left(Q_{\mathrm{E} / R T}\right)=A^{\prime \prime} \exp (\beta \sigma)$ 
$\ln \dot{\varepsilon}=\left(\frac{-Q_{E}}{R T}\right)+\ln A^{\prime \prime}+\beta \ln \sigma$

Similarly, taking logarithms of the original hyperbolic sine relation (Eq 1) have been shown to give a better relation between the Zener-Hollomon parameter and peak stress during hot deformation (Eq 7) (Ref 38, 67-71).

$\ln \dot{\varepsilon}=\ln A-\frac{Q_{\mathrm{sinh}}}{R T \ln 10}+n \ln \left[\sinh \left(\alpha \sigma_{P}\right)\right]$

$\alpha, \beta$ and $n^{\prime}$ are unknown constants that satisfy the relationship $\alpha \approx \beta / n^{\prime}$. The values of $n^{\prime}$ and $\beta$ can be derived from the gradients of relevant stress-stain data and substitution of these gradients into Eq 4 and 6.

\subsection{Establishment of Processing maps (Power Dissipation Maps)}

Processing maps are used to model the hot workability window at high temperatures and to predict conditions under which a defect-free (i.e. free of cracks or voids) microstructure may be obtained. The dynamic material modelling approach describes the material behaviour under processing conditions, assuming that the workpiece dissipates power during deformation (Ref 50, 72). During deformation, a total power, $P$, is applied to the material, which may be divided into $G$ and $J$, as described above. As well as leading to shape change, $G$, may also cause a rise in temperature $(\operatorname{Ref} 50,73)$. The materials phenomena that can account for $J$ include an increase in dislocation density and grain size (Ref 50, 73). $P, G$ and $J$ are, naturally, related and may be expressed in terms of strain rate and instantaneous stress (Eq 8). A strain rate sensitivity, $m$, is defined as the rate of change of energy stored in the microstructure with energy used to perform the deformation (Eq 9) (Ref 29-33, 35, 36, 38-41, 57, 74, 75) and allows the fraction of instantaneous power input that is used to change the microstructure to be calculated (Eq 11). $m$ has a maximum value of 1 in thermomechanical processing of metals, as a value greater than 1 implies behaviour similar to shear thinning of a liquid, where strain rate increases rapidly with small increments of stress, which is not observed in metals under stable deformation conditions (Ref 49, 72).

$$
\begin{aligned}
P & =\sigma \dot{\varepsilon}=\int_{0}^{\dot{\varepsilon}} \sigma \mathrm{d} \dot{\varepsilon}+\int_{0}^{\sigma} \dot{\varepsilon} \mathrm{d} \sigma=G+J \\
m & =\frac{\partial J}{\partial G}=\frac{\dot{\varepsilon} \partial \sigma}{\sigma \partial \dot{\varepsilon}}=\frac{\partial \sigma}{\sigma}\left(\frac{\partial \dot{\varepsilon}}{\dot{\varepsilon}}\right)^{-1}=\frac{\partial \ln (\sigma)}{\partial \ln (\dot{\varepsilon})} \\
& \approx \frac{\Delta \log (\sigma)}{\Delta \log (\dot{\varepsilon})}(\text { at a constant } T \text { and } \varepsilon) \\
m & =\frac{\int_{0}^{\sigma} \dot{\varepsilon} \mathrm{d} \sigma}{\int_{0}^{\dot{\varepsilon}} \sigma \mathrm{d} \dot{\varepsilon}}=\int_{0}^{\sigma} \frac{\partial \sigma}{\sigma} \int_{0}^{\dot{\varepsilon}}\left(\frac{\partial \dot{\varepsilon}}{\dot{\varepsilon}}\right)^{-1}=\frac{\partial \ln (\sigma)}{\partial \ln (\dot{\varepsilon})} \\
& \approx \frac{\Delta \log (\sigma)}{\Delta \log (\dot{\varepsilon})}(\operatorname{constant} T \text { and } \varepsilon)
\end{aligned}
$$

The strain rate sensitivity, $m$, quantifies the division of power between $J$ and $G$, based on the flow stress, $\sigma$, and strain rate, $\dot{\varepsilon}(\mathrm{Eq} \mathrm{11).}$
$J=\left[\frac{m}{m+1}\right] \sigma \dot{\varepsilon}$

If the flow stress of the workpiece obeys a power law at constant deformation temperature and true strain (Eq 12, Ref 76), it may be called an ideal dissipator, and $J$ reaches a maximum when $m=1$, at which point $J=G=J_{\max }=\sigma \dot{\varepsilon} / 2$. In this case, the material stores the maximum possible amount of energy in the form of microstructural changes. Such energy can be used to drive recrystallization.

$\sigma=k \dot{\varepsilon}^{m}$

In the case of workpieces that do not necessarily follow power law, the flow stress in the hot-deformed material varies with strain, strain rate and temperature in a way that is not necessarily linear (Ref 49). In this case, the parameter $\eta$, called the efficiency of power dissipation, is defined. $\eta$ represents the fraction of the power dissipation that occurs through microstructural changes in the workpiece. It may be defined in terms of $m$, providing that $m$ is constant during the deformation (Table 1).

$\eta=\frac{J}{J_{\max }}=\frac{\left.\int_{0}^{\sigma} \dot{\varepsilon} \mathrm{d} \sigma\right|_{0<m<1}}{\left.\int_{0}^{\sigma} \dot{\varepsilon} \mathrm{d} \sigma\right|_{m=1}}=\frac{\int_{0}^{\sigma} k^{-1 / m} \sigma^{1 / m} \mathrm{~d} \sigma}{\left.\int_{0}^{\sigma} \dot{\varepsilon} \mathrm{d} \sigma\right|_{m=1}}=\frac{\frac{m \sigma \dot{\varepsilon}}{(m+1)}}{\frac{\sigma \dot{\varepsilon}}{2}}=\frac{2 m}{m+1}$

The variation of $\eta$ with temperature and strain rate constitutes a processing map, which consists of various domains that may be correlated with specific deformation and microstructural evolution mechanisms. Such a map allows the definition of a "safe domain" for processing-conditions under which the material may be deformed without failure. $\eta$ may be plotted as contour map, based on the deformation temperature and strain rate (Table 2) .

Dynamic recrystallization and dynamic recovery are considered to be "safe" microstructural evolution mechanisms, where power dissipation occurs by annihilation of dislocations, and work hardening is avoided or minimised. Of these, dynamic recrystallization is more efficient at removing dislocation density than dynamic recovery and is preferred for hot working.

It is well understood that the high-temperature flow stress behaviour of a given material is strongly dependent on the deformation temperature and strain rate. Numerous studies have suggested different mathematical relations to correlate the flow stress obtained at constant temperature and strain rate. The constant temperature flow stress equation obeys a power law (Eq 12) (Ref 77). Taking natural logarithms of the power law allow the strain rate sensitivity constant, $m$, to be derived from stress-strain data (Eq 14).

$\ln \sigma=\ln k+m \ln \dot{\varepsilon}$

By comparison with (Eq 14), it may be seen that the first derivative of the quadratic equation with respect to the natural logarithm of strain rate, $\ln \dot{\varepsilon}$, gives the strain rate sensitivity, $m$, (Eq 15). The peak true stress, $\sigma_{\mathrm{P}}$, as function of strain rate can also be calculated using a polynomial expression for $\ln \left(\sigma_{\mathrm{P}}\right)$ as a function of $\ln (\dot{\varepsilon})$ for a given deformation temperature (Eq 16 , where $a, b$ and c are temperature-dependent strength parameters). It was eventually found that a second order polynomial was the most appropriate. 
Table 1 Composition of Alloy 825 used in this study

\begin{tabular}{lcccccccccc}
\hline Elements & $\mathbf{F e}$ & $\mathbf{C r}$ & $\mathbf{M o}$ & $\mathbf{C u}$ & $\mathbf{T i}$ & $\mathbf{M n}$ & $\mathbf{S i}$ & $\mathbf{N}$ & $\mathbf{C}$ \\
\hline Content & 32 & 22.0 & 2.5 & 1.6 & 0.8 & 0.7 & 0.2 & 0.009 \\
Uncertainty & $\ldots$ & 0.001 & 0.03 & 0.002 & 0.003 & $\ldots$ & $\ldots$ & 0.005 & 0.01
\end{tabular}

The residue of the alloy is nickel. All values are given in wt.\%. Levels of carbon were measured using combustion photometry. Combustion analysis was used for carbon and nitrogen. X-Ray Fluorescence spectrometry was used for other elements. Uncertainty estimates for C and $\mathrm{N}$ measurements are taken from data in standard ASTM E1018-11. The uncertainty estimates of the other elements are taken from ASTM E572-13

$\ln \sigma_{\mathrm{P}}=a+b \ln \dot{\varepsilon}+c(\ln \dot{\varepsilon})^{2}$

The strain rate sensitivity, $m$, under stable material flow is expressed by the derivative of the natural logarithm of stress with respect to that of strain (Eq $14 \mathrm{cf}$. Eq 16).

$m=\frac{\partial \ln \sigma_{P}}{\partial \ln \dot{\varepsilon}}=b+2 c \ln \dot{\varepsilon}($ at constant temperature and strain $)$

When the result of (Eq 17), becomes negative, the flow is predicted to be unstable for the relevant temperature and strain rate $(\operatorname{Ref} 78)$.

$\xi(\dot{\varepsilon})=\frac{\partial \ln \left(\frac{m}{m+1}\right)}{\partial \ln (\dot{\varepsilon})}+m=\frac{2 c}{m(m+1)}+m<0$

\section{Material and Experimental Procedure}

The material used in this investigation is Ni-based Alloy 825 (composition in Table 1). The material was melted in air in an electric arc furnace, then subjected to argon oxygen decarburization and continuously cast as blooms. The initial microstructure consists of large grains with an average grain size of $430 \pm$ $80 \mu \mathrm{m}$ (Fig. 1), measured using the linear intercept method. In accordance with ASTM E209, cylindrical compression test pieces were machined with a diameter of $10 \mathrm{~mm}$ and a length of $150 \mathrm{~mm}$. The axis of compression was parallel to the long axis of the continuously cast blooms. The samples were machined from a region of the cast where grains were found to be equiaxed.

Isothermal deformation tests were conducted on a Gleeble3500 thermomechanical simulator (Dynamic Systems Inc. (DSI), New York, NY, USA) at temperatures from 950 to $1250{ }^{\circ} \mathrm{C}$ at $50{ }^{\circ} \mathrm{C}$ intervals and strain rates range of $0.01 \mathrm{~S}^{-}$ ${ }^{1}-10.0 \mathrm{~S}^{-1}$ with intervals of an order of magnitude. Tests were performed at Sandvik Material Technology research and development (R\&D) department in Sandviken, Sweden. To reduce friction, graphite foil with a thickness between $1 \mathrm{~mm}$ and $2 \mathrm{~mm}$ was placed on each platen, and a high-temperature lubricant (nickel paste) was applied. In the case of deformation at $1200{ }^{\circ} \mathrm{C}$ or $1250{ }^{\circ} \mathrm{C}$, samples were soaked at the deformation temperature for $100 \mathrm{~s}$ and then deformed. In the case of samples deformed at temperatures below $1200{ }^{\circ} \mathrm{C}$, samples were first soaked at $1200{ }^{\circ} \mathrm{C}$ for $100 \mathrm{~s}$ to mimic industrial practice and then cooled at $5{ }^{\circ} \mathrm{C} \mathrm{S}^{-1}$ to the deformation temperature. The samples were held at the deformation temperature for $30 \mathrm{~s}$ before deformation to ensure a homogeneous temperature.
Samples were compressed by a load of $100 \mathrm{kN}$ under vacuum, before being quenched in high pressure air to a temperature of between 100 and $200{ }^{\circ} \mathrm{C}$. These conditions were selected as it has been shown that the dynamic recrystallization is unlikely to be complete, and the flow stress is likely to be affected by the cast grain structure or grain size ( $\operatorname{Ref} 27,79)$. Samples were first homogenised at a temperature between 1200 and $1250{ }^{\circ} \mathrm{C}$ and were then compressed to a height reduction of $50 \%$, corresponding to a nominal true strain of 0.7 . During testing, barrelling was found to be insignificant under conditions where measurements of peak stress and strain were made.

The deformed samples were cut parallel to the axis of compression and prepared for metallography following standard procedures. The specimens were electrochemically etched for optical microscopy (Zeiss microscopy, Oberkochen, Germany) in a solution of $10 \mathrm{~g}$ oxalic acid and $100 \mathrm{ml}$ water for between $3 \mathrm{~s}$ and $60 \mathrm{~s}$ under an applied potential of $6 \mathrm{~V}$. Quantitative measurement of grain size used the mean linear intercept method. Hardness testing was performed with Vickers method with a $500 \mathrm{~g}$ load in accordance with ASTM E384. Five indentations were made for each measurement.

Microstructural investigations were performed on sections parallel to the compression axis using Electron Backscatter Diffraction (EBSD) in a Zeiss Sigma field emission gun scanning electron microscope (Carl Zeiss Microscopy GmbH, Oberkochen, Germany). The data were acquired and processed using the software TSL OIM Analysis version 7 (AMETEK, Inc., Berwyn, PA, USA). Orientation imaging microscopy (OIM) maps and the misorientation angles of grains were calculated from the EBSD data. Grain orientation spread (GOS) was used, instead of a grain size criterion, to classify grains as either recrystallized or deformed (Ref 80-83). This was chosen as a grain size criterion can be misleading, either because dynamic recrystallized grains continue to grow without undergoing deformation at elevated deformation temperature (in which case a recrystallized grain is misclassified as a deformed grain), or parent grains severely fragment at high strain rate (in which case a deformed grain is misclassified as a recrystallized grain) (Ref 81). The GOS is defined as the average difference in orientation between the mean orientation within a grain and the orientation measurement at each point within a single grain (Ref 80-85). Data were cleaned before analysis to minimise the influence of noise on the results. This cleaning consisted of one iteration of grain dilation, with the grain tolerance angle set to $5^{\circ}$. This means that grain boundaries are defined where there is a misorientation of $5^{\circ}$ or greater. A minimum grain size of 10 pixels was also defined. When classifying the grains as recrystallized or deformed, a threshold value is defined. In literature, this is selected variously as $1,2^{\circ}, 3^{\circ}$ or $5^{\circ}(\operatorname{Ref} 80-83$, 86). In this study, the initial specimen annealed at $1200^{\circ} \mathrm{C}$ for 


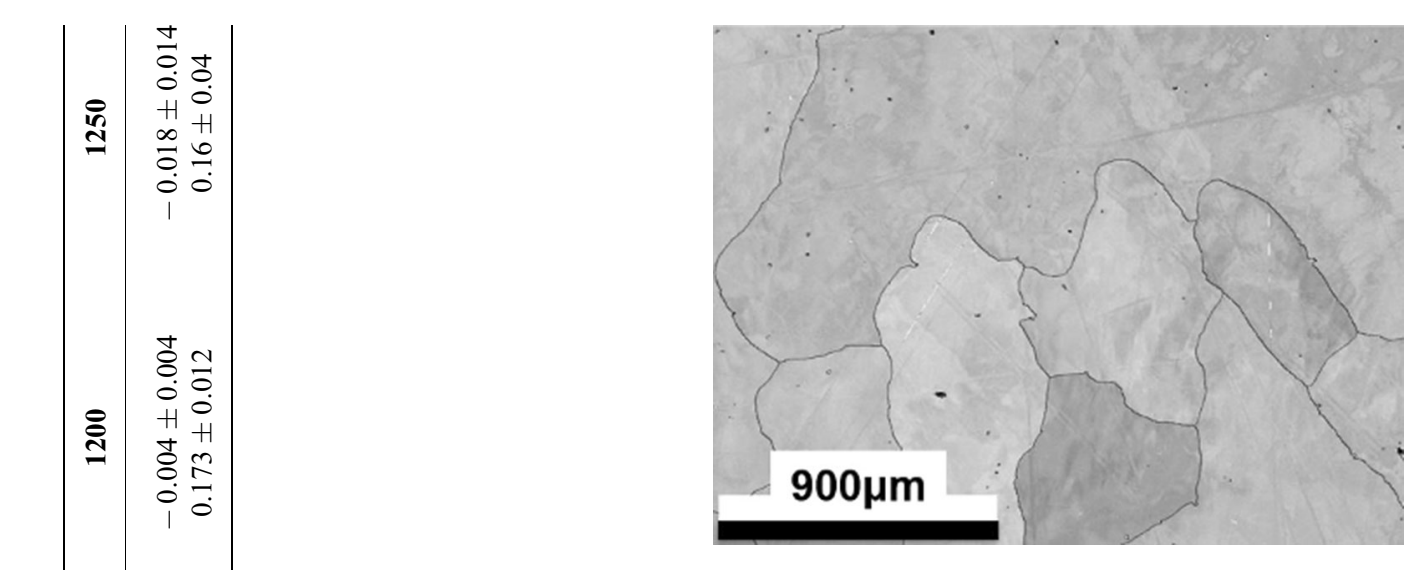

Fig. 1 EBSD micrograph (band contrast) of continuously cast bloom specimen of Alloy 825 before thermomechanical treatment

100 seconds was examined, as it is undeformed and so contains no deformed grains. It exhibits GOS $\leq 1.3^{\circ}$. The deformed specimens exhibit a broad distribution of GOS, including data above $1.3^{\circ}$, which signifies the presence of deformed grains. This value is consistent with an example from a similar study previously reported in literature (Ref 87). It is reasonable to use a threshold value of $1.3^{\circ}$, or slightly larger to account for the possibility that some recrystallized grains could have slightly higher GOS than was observed in this specimen. Therefore, in this study, a threshold value of $2.0 \mu \mathrm{m}$ was selected. Also, deformed grains are surrounded by low-angle grain boundaries, which are defined as those boundaries that exhibit a boundary rotation angle of between $2^{\circ}$ and $10^{\circ}$; grain boundaries with a rotation angle higher than $10^{\circ}$ are defined as high-angle boundaries (Ref 7).

At least 2 maps $(1734 \mu \mathrm{m} \times 2322 \mu \mathrm{m})$ with a step size of 2 $\mu \mathrm{m}$ were analysed to ensure statistical significance. All microstructures and data reported in this study are a representative of the respective samples. Grain size was measured from the EBSD maps using the mean linear intercept method. The EBSD data were obtained with a step size of $2.0 \mu \mathrm{m}$ for the undeformed material and $0.05 \mu \mathrm{m}$ for the sample deformed at $950{ }^{\circ} \mathrm{C}$ at a strain rate of $10 \mathrm{~s}^{-1}$.

\section{Results}

\subsection{True Stress-True Strain Curves}

True stress-true strain curves were obtained for different combinations of strain rates and temperatures (Fig. 2). The measured total strain in all cases was $0.68 \pm 0.04$. There is an evident work hardening at the initial stage of the deformation, and the rate of work hardening decreases with increasing strain and eventually reaches a peak. The maximum stress (peak stress) increases with increasing strain rate and decreasing temperature. At temperatures above $1100^{\circ} \mathrm{C}$, the stress-strain curves exhibit a peak in flow stress, followed by a slow strain softening and eventually reach a steady state. Test conditions were chosen to prevent significant barrelling in the strain range in which critical stress and strain occurred. During tests, no barrelling was observed until a strain of $0.4-0.5$, above which it was minimal (flow stress changed by less than $1 \%$ between a strain of 0.4 and 0.7$)$. Therefore, stress-strain data were not 
(a)

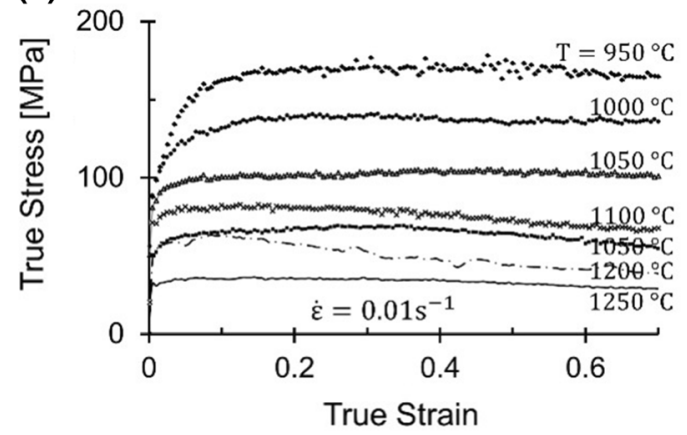

(b)

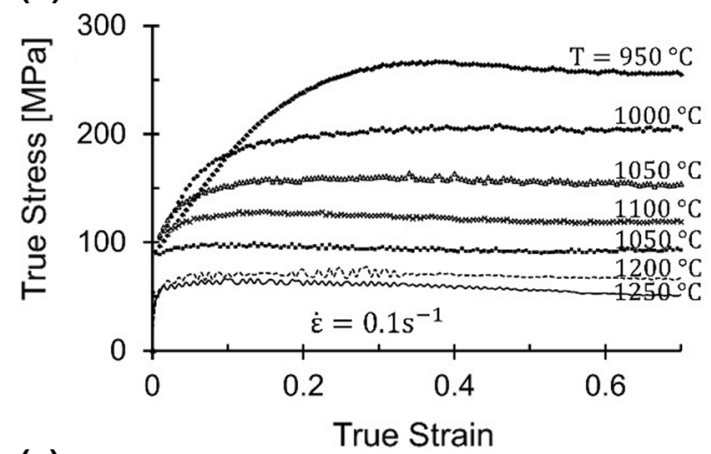

(c)
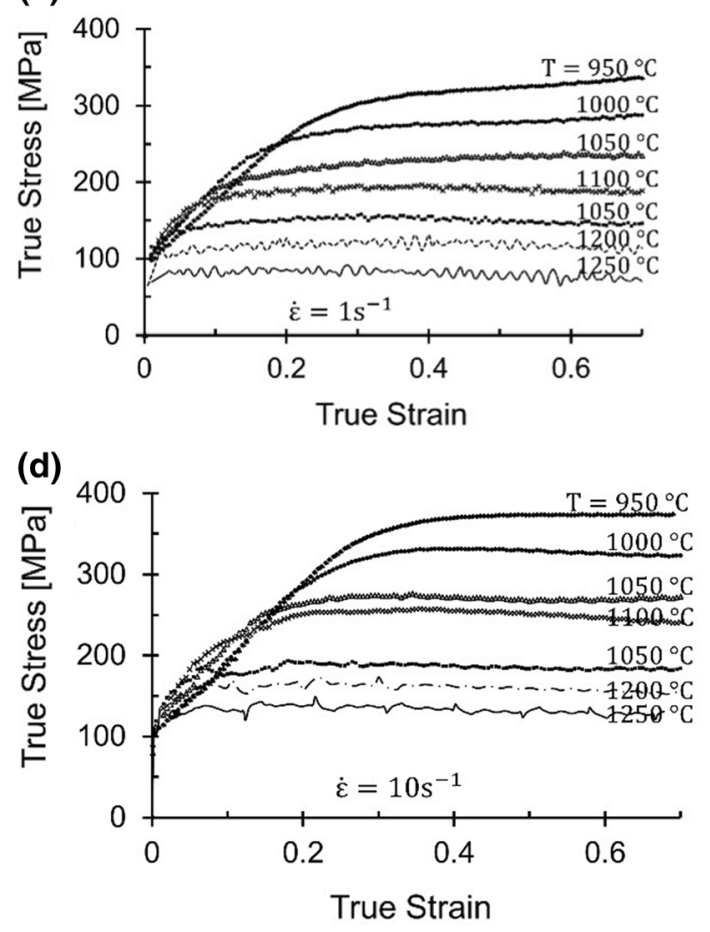

Fig. 2 True stress-true strain flow curves for equiaxed structure grain of Alloy 825 compressed at $950{ }^{\circ} \mathrm{C}$ to $1250{ }^{\circ} \mathrm{C}$ for true strain rates of (a) $0.01 \mathrm{~s}^{-1}$, (b) $0.1 \mathrm{~s}^{-1}$, (c) $1.0 \mathrm{~s}^{-1}$ and (d) $10.0 \mathrm{~s}^{-1}$ to a constant strain of 0.7

corrected for barrelling, although a correction was applied to account for the compliance of the machine, which was quantified by running a calibration procedure.

\subsection{Evaluation of the Constitutive Equation}

A second order polynomial was fitted to experimental stressstrain data by least squares regression to interpolate the data and thereby increase the number of datapoints (Ref 78). Plotting the relevant quantities allows the values of the materials constants: $\alpha, n, Q_{\text {sinh }}$ and $A$. Averaged over all experiments, $\alpha=7.083 \pm 1.183 \times 10^{-3} \mathrm{MPa}^{-1}, n=4.774 \pm$ 0.146 (Fig. 3a), $Q_{\text {sinh }}=452 \pm 17 \mathrm{~kJ} \mathrm{~mol}^{-1}$ (Fig. 3b) and $(1.55 \pm 0.11) \times 10^{16} \mathrm{~s}^{-1}$ (Fig. 3c).

The logarithmic plot of Zener-Hollomon parameter against a function of peak stress (Fig. 3c), all experimental points lie on same straight line, suggesting that the materials-dependent constants are indeed constant throughout this study. This implies that one deformation mechanism acts in all conditions, and a constitutive equation for the deformation of Alloy 825 can be written (Eq 18, where the strain rate, $\varepsilon$, is expressed in units of $\mathrm{s}^{-1}$, the temperature is expressed in Kelvin and the stress in $\mathrm{MPa}$ ).

$Z=\varepsilon \exp \left(\frac{452400}{R T}\right)=1.55 \times 10^{16}\left[\sinh \left(0.00708 \sigma_{P}\right)\right]^{4.774}$

Similarly, the flow stress can be re-written as a function of Zener-Holloman parameter by rearranging Eq 1 to give 19 .

$\sigma=\frac{1}{\alpha} \cdot \ln \left\{\left(\frac{Z}{A}\right)^{\frac{1}{n}}+\left[\left(\frac{Z}{A}\right)^{\frac{2}{n}}+1\right]^{\frac{1}{2}}\right\}$

Substituting the value derived for each parameter gives the constitutive equation of equiaxed deformed samples at peak strain, $\varepsilon_{\mathrm{P}}$ (since these values were derived using the peak stress) (Eq 20).

$\sigma_{P}=141 \ln \left\{\left(3.97 \times 10^{-4}\right) Z^{0.21}+\left[\left(1.58 \times 10^{-7}\right) Z^{0.42}+1\right]^{1 / 2}\right\}$

\subsection{Quantification of the Process Map}

Plotting the natural logarithm of peak stress against that of strain rate (Fig. 4) allows the derivation of the gradient, which is the strain rate sensitivity, $m$ (Eq 16). This may be used to derive the materials constants $b$ and $c$ (Eq 16). The results are summarised in. The strain rate sensitivity can then be used to calculate the efficiency of power dissipation for each deformation condition. According to dynamic materials modelling, one can draw different processing maps with the $\eta$ calculated with Eq 13, 15 or 16. Datapoints on the map were interpolated form the measurement data using the software MATLAB (version $2020 \mathrm{~b}$ ) based on a cubic spline and least squares polynomial regression. For simplicity, the entire processing map has been interpreted as containing four major domains which are marked as I-III and "instability".

Optical microscopy revealed that the as-deformed microstructures are dominated by an austenitic matrix and are free from intermetallic phases; the only precipitate found was primary TiN (Fig. 6a-d). After deformation at a temperature of $1150{ }^{\circ} \mathrm{C}$ and a strain rate of $0.01 \mathrm{~s}^{-1}$, the material contains 

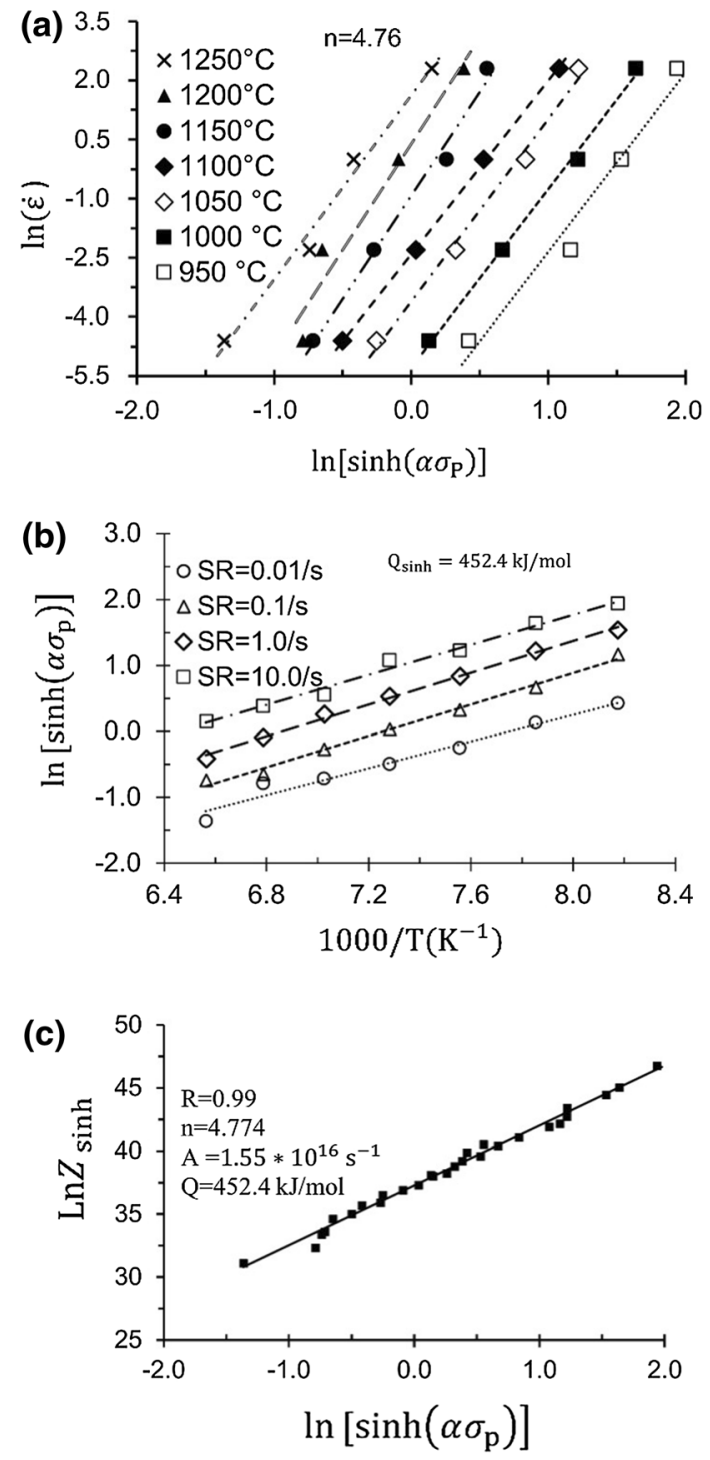

Fig. 3 (a) Relationship of the natural logarithm of strain rate, $\ln \dot{\varepsilon}$, against the natural logarithm of the hyperbolic sine function of peak stress, $\ln \left[\sinh \left(\alpha \sigma_{\mathrm{p}}\right)\right]$, for different deformation temperatures for determining material parameter, $n$, for equiaxed specimens, (b) variation of the inverse of temperature with the hyperbolic sine function of peak stress, $\ln \left[\sinh \left(\alpha \sigma_{\mathrm{p}}\right)\right]$, at different strain rates for determining the deformation activation energy $\left(Q_{\text {sinh }}\right)$ and (c) The relation between the peak stress and the relevant Zener-Hollomon parameter, $\ln Z_{\text {sinh }}$

coarse grains with a high proportion of high-angle grain boundaries (Fig. 6a). After the material was deformed at a temperature of $1100{ }^{\circ} \mathrm{C}$ and a strain rate of $0.1 \mathrm{~s}^{-1}$, an elongated structure and small recrystallized grains were observed (Fig. 6b). However, necklace structures, serrated grain boundaries, non-recrystallized deformed grains and grains formed by particle stimulated nucleation (PSN) could be observed following deformation at lower temperatures (Fig. 6c and d). Following deformation at the lowest temperature studied $\left(950{ }^{\circ} \mathrm{C}\right)$, and the highest strain rate studied $\left(10 \mathrm{~s}^{-1}\right)$, electron backscatter diffraction (EBSD) data (Fig. 7) were analysed and indicated the presence of subgrain boundaries (Fig. 7a). This is likely to result in localised work hardening and unstable deformation. Another example to fully illustrate the instability, deformed grains dominated the entire equiaxed structure, as shown in Fig. 7b. Grain orientation spread analysis was used to identify grains that were recrystallized (Table 3).

\subsection{Hardness Measurements}

Vickers hardness was measured in samples as a function of deformation strain rate and temperature (Fig. 8). The datapoints in the map were interpolated using a cubic spline and least squares regression in the software MATLAB (version 2020b).

\section{Discussion}

\subsection{Stress-Strain Behaviour}

The flow behaviour indicated by Error! Reference source not found. is in agreement with the results of previous investigations ( $\operatorname{Ref} 27,79,88)$. An existing model proposes that dynamic recovery consists of two competing processes: the generation of dislocations and the annihilation of dislocations (Ref $6,49,89)$. The relative rate of these two processes will determine the shape of stress-strain curves: if the rate of dislocation annihilation is larger than that of generation, it will result in flow softening. If dislocation annihilation is slower than dislocation generation, flow stress will continuously increase and lead to work hardening. If a balance is established between these two rates, a steady flow stress can be observed. The results indicate that all conditions led to initial work hardening, but that a balance was established in most cases (Fig. 2). This is common for hot deformation of metals. In some cases, work hardening persisted for the entire deformation. This was favoured by low temperatures and high strain rates (e.g. $950{ }^{\circ} \mathrm{C}$ and $\left.1.0 \mathrm{~s}^{-1}\right)$. Conversely, high temperatures favoured strain softening, especially at low strain rates.

\subsection{Constitutive Equation Analysis}

The value of $n=4.774$ (Fig. 3a) indicates that the deformation is governed by the glide and climb of dislocations, in which case theory predicts that $n=5$ (Ref 90). The activation energy for plastic deformation, $Q_{\text {sinh }}=452 \pm 17 \mathrm{~kJ} \mathrm{~mol}^{-1}$ ) is quite close to that reported in the previous study on the deformation activation energy reported by the same authors (Ref 30$)$. This value is also within the range of activation values reported for nickel-base

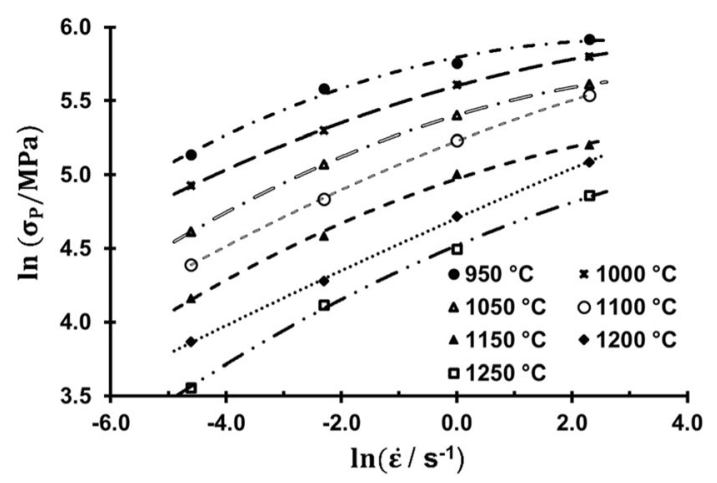

Fig. 4 Variation of peak stress, $\ln \sigma_{\mathrm{P}}$, versus strain rate, $\ln \dot{\varepsilon}$ at different deformation temperatures. This plot is used to derive the materials parameters $b$ and $c$ 
superalloys: $416.6 \mathrm{~kJ} \mathrm{~mol}^{-1}$ (Ref 91), $438 \mathrm{~kJ} \mathrm{~mol}^{-1}$ (Ref 92), $450.8 \mathrm{~kJ} \mathrm{~mol}^{-1}$ (Ref 74), $451 \mathrm{~kJ} \mathrm{~mol}^{-1}(\operatorname{Ref} 75), 465 \mathrm{~kJ} \mathrm{~mol}^{-1}$ (Ref 20), $472 \mathrm{~kJ} \mathrm{~mol}^{-1}$ (Ref 76) and $486 \mathrm{~kJ} \mathrm{~mol}^{-1}$ (Ref 13). However, it is higher than values obtained for this alloy in other studies: $438 \mathrm{~kJ} \mathrm{~mol}^{-1}$ (Ref 92) and 416.6 $\mathrm{kJmol}^{-1}(\operatorname{Ref} 91)$. The former used peak stress data measured in wrought samples of a different size to the current study and the latter in extruded material. Neither can be compared with confidence to the current study and both lie within the range of deformation activation energy listed above. The deformation of nickel-based alloys is usually controlled by the climb of dislocations around obstacles(Ref 20). The measured activation energy in the current study is greater than the activation energy of selfdiffusion in nickel $\left(280 \mathrm{~kJ} \mathrm{~mol}^{-1}\right)$ (Refs 46, 73). This implies that some other mechanism is limiting. Moreover, the activation energy for deformation is affected by peak stress, $\sigma_{P}$ and stress exponent, $n$ (Eq 7). Both $\sigma_{P}$ and $n$ are related to microstructural features such as precipitates and grain size. As a result, the activation energy for deformation must also vary with the microstructure, which reflects the complex interaction between the kinetics of the various processes by which dislocations are generated, annihilated and pinned (Ref 93). Precipitates can inhibit dislocation glide, dislocation climb and grain boundary movement, and it is known that Alloy 825 contains precipitates. Thus, the mean value of the deformation activation energy for Alloy 825 is much larger than the self-diffusion activation energy of pure nickel.

\subsection{Efficiency of Power Dissipation and Microstructural Analysis}

A strain of 0.7 represents the situation at flow softening state or the steady state, depending on the deformation temperature (Fig. 2). The efficiency of power dissipation, $\eta$, is dependent on the strain rate sensitivity index, $m$, and the microstructural changes during deformation (Eq 9 and 13). Therefore, it follows that microstructural evolution can be predicted by analysing the value of $\eta$ (and validated using metallography). The domains in processing maps can also be characterised based on the resulting microstructure [18]. The power dissipation maps developed at the strain of 0.7 exhibit four different domains with relatively high peak efficiencies of power

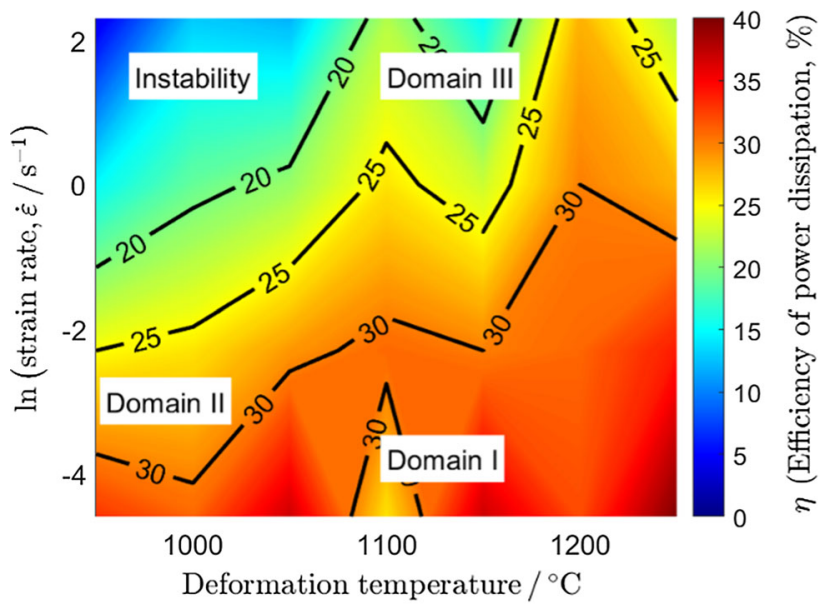

Fig. 5 Processing map for as-cast Alloy 825 at a true strain of 0.7 . The contour values show the efficiency of power dissipation in percent
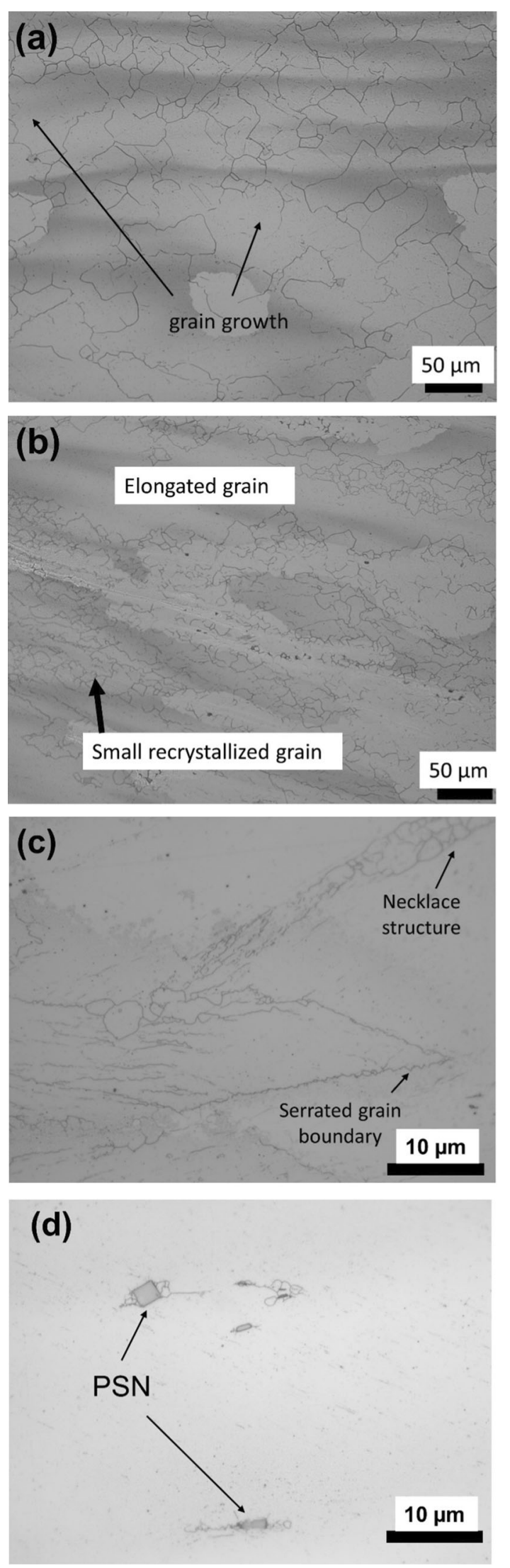

Fig. 6 Representative microstructures of the 825 alloy deformed at (a) $1150{ }^{\circ} \mathrm{C}, 0.01 \mathrm{~s}^{-1}$ (domain I); (b) $1100{ }^{\circ} \mathrm{C}, 0.1 \mathrm{~s}^{-1}$ (domain II); (c) $1000{ }^{\circ} \mathrm{C}, 10 \mathrm{~s}^{-1}$ (domain III); (d) $950{ }^{\circ} \mathrm{C}, 10 \mathrm{~s}^{-1}$ (Instability) 
dissipation (Fig. 5). It is worth noting that there is enough time for nucleation and growth process at the lowest strain rate $(0.01$ $\left.\mathrm{s}^{-1}\right)$. This is reflected in the fact that the volume fraction of dynamically recrystallized grains at low strain rates is significantly larger than at higher strain rates (Fig. 6a, Table 3).

The processing map (Fig. 5) exhibits four different domains of deformation efficiency in the temperature and strain rate ranges. Domain I describes the range of conditions in which large $(23.5 \pm 1.4 \mu \mathrm{m})$ dynamically recrystallized grains form (e.g. Fig. 6(a). Because the mobility of grain boundaries is enhanced as solute drag diminished with increasing deformation temperature $(\operatorname{Ref} 6)$. This is consistent with hot-worked $\mathrm{Ni20Cr}$ (grain size $\approx 45 \mu \mathrm{m}$ ) in previous studies, which show a peak efficiency of approximately $38 \%$ at a total true strain of 0.5 , deformation temperature of $1200{ }^{\circ} \mathrm{C}$ and a strain rate of $0.1 \mathrm{~s}^{-1}$ (Ref 5). Similar alloys begin recrystallization with the formation of twins (Ref 8).

Domain II exhibits a power dissipation efficiency value (25\%-30\%) between values typical of full dynamic recovery (15\%-25\%) and pure dynamic recrystallization (30-40\%), which implies that both mechanisms are active simultaneously and compete with each other. A typical microstructure in domain II shows many elongated grains and a large number of small $(6.5 \pm 0.1 \mu \mathrm{m})$ recrystallized grains (Fig. 6b). Grain boundary mobility is lower than in Domain I, and the faster strain does not allow grain boundaries to move during deformation. Therefore, no significant grain growth was observed in domain II. Adiabatic heating of the samples has been suggested as a mechanism that contributes to strain softening effects under such conditions (Ref 94).

Domain III represents temperatures between 950 and $1100{ }^{\circ} \mathrm{C}$ and strain rates above $0.1 \mathrm{~s}^{-1}$. The microstructure is inhomogeneous with serrated grain boundaries and necklace structures (e.g. Fig. 6c). The necklace structure is indicative of grain boundary bulging, which suggests ongoing recrystallization. This is consistent with observed trends in a nickel-base superalloy similar to the alloy being studied here (Ref 95). Under the conditions of low or moderate temperature and high strain rate, a very high dislocation density will be developed, which will provide many nucleation sites for, and increase the driving force of, recrystallization ( $\operatorname{Ref} 18,50)$. This leads to the conclusion that the fine grain structure is caused by extensive nucleation of dynamically recrystallized grains, but grain growth is limited by the short deformation time and limited temperature.

The material exhibits flow instability below $1100{ }^{\circ} \mathrm{C}$ and at a strain rate above $0.3 \mathrm{~s}^{-1}$. The microstructure exhibits a substructure that formed during the deformation, eliminating the possibility that recrystallization occurred. This is consistent with a previous study, in which a similar substructure dominates the material (Ref 79). In addition, some heavily deformed structures were found to be localised (Fig. 7a). This occurs because flow stress localization easily occurs at high strain rates, where dislocations form easily in regions already
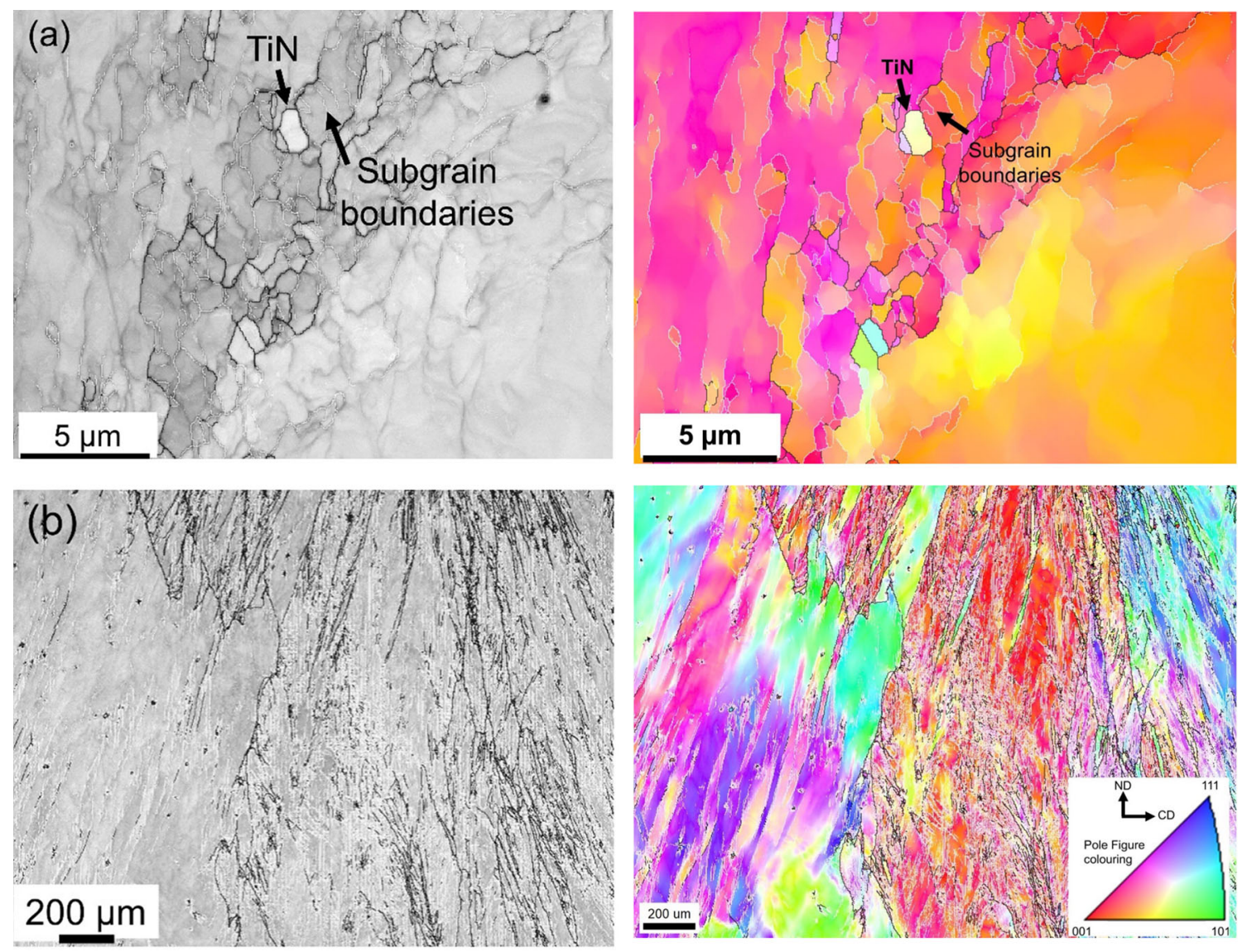

Fig. 7 EBSD images (band contrast) of equiaxed compressed specimen of an Alloy 825 after a uniaxial compression to a nominal strain of 0.7 and a strain rate of $10 \mathrm{~s}^{-1}$ at the deformation temperature of $950{ }^{\circ} \mathrm{C}$, (a) 500x magnification (b) 50x magnification, each overlaid with high-angle (black) and low-angle (white) grain boundaries. A colour version of this figure is available online. 
Table 3 Extent of recrystallization in selected samples from the current study

\begin{tabular}{lcr}
\hline Deformation temperature, ${ }^{\circ} \mathbf{C}$ & ${\text { Strain rate, } \mathbf{s}^{-\mathbf{1}}}$ & Percentage of grains th $^{-1}$ \\
\hline 1150 & 0.01 & 44 \\
1100 & 0.1 & 14 \\
1000 & 10.0 & 7 \\
950 & 10.0 & 2
\end{tabular}

Both high temperature and low strain rate promote recrystallization

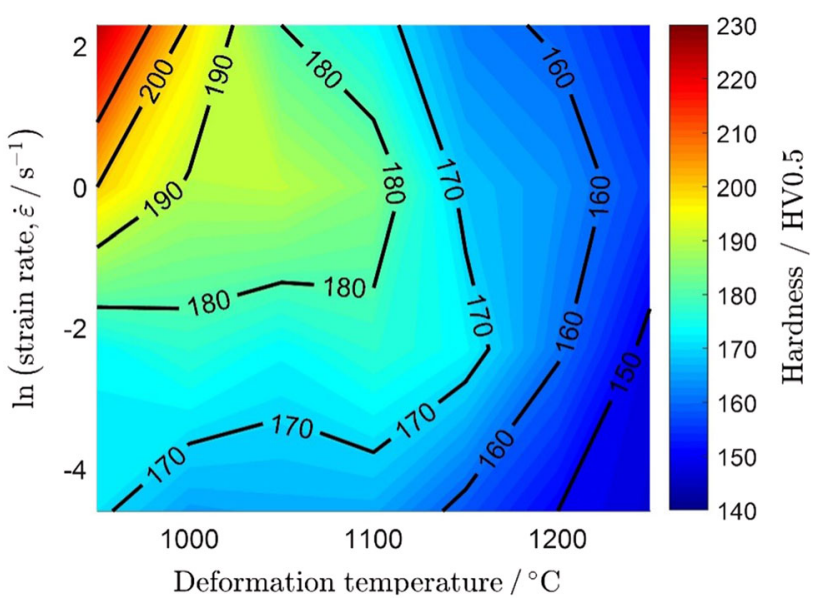

Fig. 8 Hardness map of hardness with strain rate and temperature at a strain of 0.7

containing a high dislocation density (Ref 38, 46). Dispersed particles of titanium nitride (TiN) are present, and dislocations were especially dense around such particles during deformation (Fig. 7a). This was also observed in a previous study (Ref 27). When the size of a TiN particle is greater than $0.5 \mu \mathrm{m}$, they can stimulate dynamic recrystallization, which was observed here (Fig. 6d) and is referred to as particle stimulated nucleation (Ref 6).

There is no distinct (sharp) boundary between these domains and the exact values at which the boundaries between domains were defined in Fig. 5 that are taken at convenient values of the power dissipation efficiency, although they are appropriate according to the definitions above. The instability domain was defined to exist where the power dissipation efficiency was below $20 \%$. Domain III was defined at values between $20 \%$ and $25 \%$, domain II between $25 \%$ and $30 \%$ and domain I above $30 \%$.

Therefore, for Alloy 825, it is preferable to conduct any hot working at a temperature between 1100 and $1250{ }^{\circ} \mathrm{C}$ at a strain rate between $0.01 \mathrm{~s}^{-1}$ and $0.1 \mathrm{~s}^{-1}$ (Domain I). This gives the highest achievable power dissipation efficiency. It is necessary to avoid working the alloy in the temperature range of 950$1100{ }^{\circ} \mathrm{C}$ for a strain rate of above $0.3 \mathrm{~s}^{-1}$, as this leads to "instability". This is because dynamic recrystallization may not be completed under such conditions (Fig. 6a cf. Fig. 6d).

The model used in the current study does not clearly define the partial and/or non-recrystallized regimes. Significant advances in the understanding of microstructural refinement through thermomechanical processing have shown different ways to produce a well-conditioned microstructure during hot deformation. Therefore, the combined use of hot deformation maps using the Dynamic Materials Modelling approach and the application of well-known physical models, such as those that account for recrystallization, total strain and temperature or recrystallization, temperature and time can provide a powerful tool to the understanding of microstructural optimization through thermomechanical processing. The power dissipation efficiency, $\eta$, is an important parameter for the determination of the extent of power dissipation by microstructural changes during hot deformation. The optimum hot working condition is when $\eta$ is maximum, and the maximum possible energy is stored as microstructural changes, such as recrystallization and recovery.

\subsection{Hardness}

It is evident that hardness depends strongly on deformation temperature and strain rate (Fig. 8). These results are in agreement with the dynamic material model (Fig. 5). The hardness values for compressed specimens increases with decreased deformation temperature and increased strain rate. This is because increasing the temperature leads to more extensive recrystallization (Table 3, Fig. 6). This will remove dislocation density and lead to softening. An increase in strain rate reduces the total time available for recrystallization. Strain hardening arises from the formation of a substructure of dislocations in the matrix (Fig. 7) and leads to a higher hardness (225 HV0.5). No void formation occurred at the hard titanium nitride (TiN) particles (Fig. 6d). Additionally, it is suggested that the processes of recrystallization and recovery are active and influence the softening of the material.

\section{Conclusions}

The hot deformation behaviour of the equiaxed-grain specimens of continuously cast blooms of Alloy 825 was investigated. Deformation occurred at temperatures between 950 and $1250{ }^{\circ} \mathrm{C}$ and at strain rates from 0.01 to $10.0 \mathrm{~s}^{-1}$. The efficiency of power dissipation and the hardness of the resulting microstructures were assessed.

(1) The flow stress is both strain rate and temperature-dependent. It increases with increasing strain rate and decreasing temperature. The peak true flow stress of Alloy 825 can be represented by the following equation:

$$
Z=\dot{\varepsilon} \exp \left(Q_{\sinh } / R T\right) \approx A[\sinh (\alpha \sigma)]^{n}
$$

(2) The average activation energy for hot deformation, $Q_{\text {sinh }}$ was determined to be $450 \mathrm{kJmol}^{-1}$. The average value of $\alpha$ was determined to be $7.1 \times 10^{-3}$. The hot flow beha- 
viour can be described well by the hyperbolic-sine-type equation. The mean creep exponent, $n$, was found to be a close to value of 5 hence the hot deformation in equiaxed compressed specimens is governed by the glide and climb of dislocations.

(3) In the process map, a domain at a deformation temperature.of between 1100 and $1250{ }^{\circ} \mathrm{C}$, with a strain rate of between $0.01 \mathrm{~s}^{-1}$ and $0.1 \mathrm{~s}^{-1}$ gives the optimum hot deformation condition. It exhibits a high power dissipation efficiency (up to $35 \%$ ) and can result in fine recrystallized microstructure.

(4) The hot processing map suggests good workability for a wide range of conditions with a strain rate, $\dot{\varepsilon}<0.1 s-1$ and a temperature of $1100{ }^{\circ} \mathrm{C}$ or higher.

(5) The optimum processing parameters for good strain hardening are obtained in the temperature range of between 950 and $1100{ }^{\circ} \mathrm{C}$ with a strain rate of $0.3 \leq \dot{\varepsilon} / \mathrm{s}^{-1} \leq 10.0$.

\section{Acknowledgments}

MA would like to thank AB Sandvik Materials Technology for the financial support, and the permission to publish this paper. This research did not receive any specific grant from funding agencies in the public, commercial or not-for-profit sectors.

\section{Funding}

Open access funding provided by Royal Institute of Technology.

\section{Data Availability}

The raw data required to reproduce these findings are available upon request to the corresponding author. The processed data required to reproduce these findings are available to upon request to the corresponding author.

Open Access This article is licensed under a Creative Commons Attribution 4.0 International License, which permits use, sharing, adaptation, distribution and reproduction in any medium or format, as long as you give appropriate credit to the original author(s) and the source, provide a link to the Creative Commons licence, and indicate if changes were made. The images or other third party material in this article are included in the article's Creative Commons licence, unless indicated otherwise in a credit line to the material. If material is not included in the article's Creative Commons licence and your intended use is not permitted by statutory regulation or exceeds the permitted use, you will need to obtain permission directly from the copyright holder. To view a copy of this licence, visit http://creativecommons.org/licenses/by/4.0/.

\section{References}

1. N. Sayyar, M. Shamanian, B. Niroumand, J. Kangazian and J.A. Szpunar, EBSD Observations of Microstructural Features and Mechanical Assessment of INCOLOY 825 Alloy/AISI 321 Stainless Steel
Dissimilar Welds, J. Manuf. Process., 2020, 60, p 86-95. https://doi. org/10.1016/j.jmapro.2020.10.042

2. L. Shoemaker and J. Crum, Processing and Fabricating Alloy 825 for Optimized Properties and Corrosion Resistance, Corrosion, 2011, 2011, p 1-13.

3. B.M. Adam, J.D. Tucker and G. Tewksbury, Comparative Study of the Hot Processing Behavior in Advanced Ni-Based Superalloys for Use in A-USC Applications, J. Alloys Compd., 2020, 818, p 152907. https://d oi.org/10.1016/j.jallcom.2019.152907

4. F.L. Sui, L.X. Xu, L.Q. Chen and X.H. Liu, Processing Map for Hot Working of Inconel 718 Alloy, J. Mater. Process. Technol., 2011, 211(3), p 433-440. https://doi.org/10.1016/j.jmatprotec.2010.10.015

5. Y.V.R.K. Prasad, K.P. Rao, S. Sasidhar, Hot Working Guide: A Compendium of Processing Maps, 6. Nickel Alloys, S. Prasad, Y.V.R.K. Rao, K.P. Sasidhara, Ed., Second Edi, (Materials Park, $\mathrm{OH})$, ASM International, 2015, p 430-461

6. J. Humphreys, G.S. Rohrer, and A. Rollett, "Recrystallization and Related Annealing Phenomena," Second edi, (Amsterdam, Netherlands), Elsevier, 2004, https:/www.sciencedirect.com/science/book/97 80080426853

7. R.D. Doherty, D.A. Hughes, F.J. Humphreys, J.J. Jonas, D.J. Jensen, M.E. Kassner, W.E. King, T.R. McNelley, H.J. McQueen and A.D. Rollett, Current Issues in Recrystallization: A Review, Mater. Sci. Eng. $A, 1997$, 238(2), p 219-274. https://doi.org/10.1016/S0921-5093(97) 00424-3

8. C.I. Garcia, D.E. Camus, E.A. Loria, and A.J. DeArdo, Microstructural Refinement of As-Cast Alloy 718 Via Thermomechanical Processing, 2012, p 925-941

9. R. Raj, Development of a Processing Map for Use in Warm-Forming and Hot-Forming Processes, Metall Trans A Phys Metall Mater Sci, 1981, 12(6), p 1089-1097.

10. R. Sandström and R. Lagneborg, A Controlling Factor for Dynamic Recrystallisation, Scr. Metall., 1975, 9(1), p 59-65.

11. C.M. Sellars, W.J. McG Tegart, C.M. Sellars and W.J.M. Tegart, Hot Workability, Inter. Met. Rev., 1972, 17(1), p 1-24. https://doi.org/10. 1179/imtlr.1972.17.1.1

12. J.J. Jonas, C.M. Sellars and W.J.M. Tegart, Strength and Structure under Hot-Working Conditions, Metall. Rev., 1969, 14(1), p 1-24. h ttps://doi.org/10.1179/mtlr.1969.14.1.1

13. M. Yu, J. Li, H. Tang and Y. Bao, Hot Working Characteristics of Corrosion-Resistant Alloys G3 and 825, J. Iron Steel Res. Int., 2011, 18(4), p 68-72. https://doi.org/10.1016/S1006-706X(11)60053-8

14. A. Momeni and K. Dehghani, Microstructural Evolution and Flow Analysis during Hot Working of a Fe-Ni-Cr Superaustenitic Stainless Steel, Metall. Mater. Trans. A Phys. Metall. Mater. Sci., 2011, 42(7), p 1925-1932.

15. A. Dehghan-Manshadi, M.R.R. Barnett and P.D.D. Hodgson, Hot Deformation and Recrystallization of Austenitic Stainless Steel: Part I Dynamic Recrystallization, Metall. Mater. Trans. A, 2008, 39(6), p 1359-1370. https://doi.org/10.1007/s11661-008-9512-7

16. K. Huang and R.E. Logé, Microstructure and Flow Stress Evolution during Hot Deformation of 304L Austenitic Stainless Steel in Variable Thermomechanical Conditions, Mater. Sci. Eng. A, 2017, 2018(711), p 600-610. https://doi.org/10.1016/j.msea.2017.11.042

17. M.S. Ghazani and B. Eghbali, Characterization of the Hot Deformation Microstructure of AISI 321 Austenitic Stainless Steel, Mater. Sci. Eng. A, 2018, 730, p 380-390. https://doi.org/10.1016/j.msea.2018.06.025

18. S.S. Satheesh Kumar, T. Raghu, P.P. Bhattacharjee, G. Appa Rao and U. Borah, Constitutive Modeling for Predicting Peak Stress Characteristics during Hot Deformation of Hot Isostatically Processed NickelBase Superalloy, J. Mater. Sci., 2015, 50(19), p 6444-6456.

19. T. Sakai, A. Belyakov, R. Kaibyshev, H. Miura and J.J. Jonas, Dynamic and Post-Dynamic Recrystallization under Hot, Cold and Severe Plastic Deformation Conditions, Prog. Mater. Sci., 2014, 60(1), p 130207. https://doi.org/10.1016/j.pmatsci.2013.09.002

20. L. Wang, F. Liu, J.J.J. Cheng, Q. Zuo and C.F.F. Chen, Hot Deformation Characteristics and Processing Map Analysis for Nickel-Based Corrosion Resistant Alloy, J. Alloys Compd., 2015, 623, p 69-78. https://doi.org/10.1016/j.jallcom.2014.10.034

21. Y.C. Lin and X.-M. Chen, A Critical Review of Experimental Results and Constitutive Descriptions for Metals and Alloys in Hot Working, Mater. Des., 2011, 32(4), p 1733-1759.

22. X.M. Chen, Y.C. Lin, D.X. Wen, J.L. Zhang and M. He, Dynamic Recrystallization Behavior of a Typical Nickel-Based Superalloy 
during Hot Deformation, Mater. Des., 2014, 57, p 568-577. https://doi. org/10.1016/j.matdes.2013.12.072

23. E.I. Poliak and J.J. Jonas, A One-Parameter Approach to Determining the Critical Conditions for the Initiation of Dynamic Recrystallization, Acta Mater., 1996, 44(1), p 127-136. https://doi.org/10.1016/1359-64 54(95)00146-7

24. E.I. Poliak and J.J. Jonas, Critical Strain for Dynamic Recrystallization in Variable Strain Rate Hot Deformation, ISIJ Int., 2003, 43(5), p 692 700. https://doi.org/10.2355/isijinternational.43.692

25. W. Roberts and B. Ahlblom, A Nucleation Criterion for Dynamic Recrystallization during Hot Working, Acta Metall., 1978, 26(5), p 801-813.

26. W. Roberts, H. Boden and B. Ahlblom, Dynamic Recrystallization Kinetics, Met. Sci., 1979, 13(3-4), p 195-205. https://doi.org/10.1179/ msc.1979.13.3-4.195

27. M. Al-Saadi, F. Sandberg, A. Karasev, and P. Jönsson, "Comparative Study of Microstructures Evolution of Columnar and Equiaxed Grain Structurs in Alloy 825 after Hot Compression," 3rd International Conference on Ingot Casting, Rolling and Forging, ICRF2018, (Stockholm, Sweden), 2018, p 107-115

28. G. Varela-Castro, J.-M. Cabrera and J.-M. Prado, Critical Strain for Dynamic Recrystallisation. The Particular Case of Steels, Metals Basel., 2020, 10(1), p 135. https://doi.org/10.3390/met10010135

29. E.I. Poliak and J.J. Jonas, Initiation of Dynamic Recrystallization in Constant Strain Rate Hot Deformation, ISIJ Int., 2003, 43(5), p 684 691. https://doi.org/10.2355/isijinternational.43.684

30. M. Al-Saadi, W. Mu, C.N. Hulme-Smith, F. Sandberg and P.G. Jönsson, Effect of Trace Magnesium Additions on the Dynamic Recrystallization in Cast Alloy 825 after One-Hit Hot-Deformation, Metals Basel, 2020, 11(1), p 36. https://doi.org/10.3390/met11010036

31. F.W. Kang, X.M. Zhang, J.F. Sun and J.L. Zhao, Hot Deformation Behavior and Processing Map of a Nickel-Base Superalloy GH4169, Adv. Mater. Res., 2013, 834-836, p 432-436.

32. Q.L. Pan, B. Li, Y. Wang, Y.W. Zhang and Z.M. Yin, Characterization of Hot Deformation Behavior of Ni-Base Superalloy Rene'41 Using Processing Map, Mater. Sci. Eng. A, 2013, 585, p 371-378. https://doi. org/10.1016/j.msea.2013.07.066

33. P. Zhang, C. Hu, C. Gang Ding, Q. Zhu and H. Yong Qin, Plastic Deformation Behavior and Processing Maps of a Ni-Based Superalloy, Mater. Des., 2015, 65(2014), p 575-584. https://doi.org/10.1016/j.ma tdes.2014.09.062

34. S.V.S. Narayana Murty and B. Nageswara Rao, On the Hot Working Characteristics of INCONEL Alloy MA 754 Using Processing Maps, Scand. J. Metall., 2000, 29(4), p 146-150.

35. J. Wang, D. Liu, Y. Hu, Y. Yang and X. Zhu, Effect of Grain Size Distribution on Processing Maps for Isothermal Compression of Inconel 718 Superalloy, J. Mater. Eng. Perform., 2016, 25(2), p $677-$ 686.

36. J. Wang, J.-X. Dong and M.-C. Zhang, Nucleation Mechanisms of Dynamic Recrystallization for G3 Alloy during Hot Compression, Rare Met, 2016, 35(7), p 543-550. https://doi.org/10.1007/s12598-016-071 $8-3$

37. N.R. Jaladurgam and A.K. Kanjarla, Hot Deformation Characteristics and Microstructure Evolution of Hastelloy C-276, Mater. Sci. Eng. A, 2018, 712, p 240-254. https://doi.org/10.1016/j.msea.2017.11.056

38. S. Guo, D. Li, H. Pen, Q. Guo and J. Hu, Hot Deformation and Processing Maps of Inconel 690 Superalloy, J. Nucl. Mater., 2011, 410(1-3), p 52-58. https://doi.org/10.1016/j.jnucmat.2010.12.309

39. Y. Kong, P. Chang, Q. Li, L. Xie and S. Zhu, Hot Deformation Characteristics and Processing Map of Nickel-Based C276 Superalloy, J. Alloys Compd., 2015, 622, p 738-744. https://doi.org/10.1016/j.jallc om.2014.10.118

40. D.G. He, Y.C. Lin, M.S. Chen, J. Chen, D.X. Wen and X.M. Chen, Effect of Pre-Treatment on Hot Deformation Behavior and Processing Map of an Aged Nickel-Based Superalloy, J. Alloys Compd., 2015, 649, p 1075-1084. https://doi.org/10.1016/j.jallcom.2015.07.213

41. S. Guo, D. Li, Q. Guo, Z. Wu, H. Peng and J. Hu, Investigation on Hot Workability Characteristics of Inconel 625 Superalloy Using Processing Maps, J. Mater. Sci., 2012, 47(15), p 5867-5878.

42. Z. Shi, X. Yan and C. Duan, Characterization of Hot Deformation Behavior of GH925 Superalloy Using Constitutive Equation, Processing Map and Microstructure Observation, J. Alloys Compd., 2015, 652, p 30-38. https://doi.org/10.1016/j.jallcom.2015.08.118
43. H.T. Zhou, R.R. Liu, Z.C. Liu, X. Zhou, Q.Z. Peng, F.H. Zhong and Y. Peng, Hot Deformation Characteristics of GH625 and Development of a Processing Map, J. Mater. Eng. Perform., 2013, 22(9), p 2515-2521.

44. D.X. Wen, Y.C. Lin, H. Bin Li, X.M. Chen, J. Deng and L.T. Li, Hot Deformation Behavior and Processing Map of a Typical Ni-Based Superalloy, Mater. Sci. Eng. A, 2014, 591, p 183-192. https://doi.org/ 10.1016/j.msea.2013.09.049

45. E. Pu, W. Zheng, Z. Song, H. Feng and H. Dong, Hot Deformation Characterization of Nickel-Based Superalloy UNS10276 through Processing Map and Microstructural Studies, J. Alloys Compd., 2017, 694, p 617-631. https://doi.org/10.1016/j.jallcom.2016.10.029

46. E. Pu, W. Zheng, J. Xiang, Z. Song and J. Li, Hot Deformation Characteristic and Processing Map of Superaustenitic Stainless Steel S32654, Mater. Sci. Eng. A, 2014, 598, p 174-182.

47. K.A. Babu, S. Mandal, C.N. Athreya, B. Shakthipriya and V.S. Sarma, Hot Deformation Characteristics and Processing Map of a Phosphorous Modified Super Austenitic Stainless Steel, Mater. Des., 2017, 115, p 262-275. https://doi.org/10.1016/j.matdes.2016.11.054

48. S.C. Medeiros, Y.V.R.K. Prasad, W.G. Frazier and R. Srinivasan, 189 Modeling Grain Size During Hot Deformation of in 718, Scripta Mater, 2000, 42, p 17-23.

49. Y.V.R.K. Prasad and T. Seshacharyulu, Modelling of Hot Deformation for Microstructural Control, Int. Mater. Rev., 1998, 43(6), p 243-258. h ttps://doi.org/10.1179/imr.1998.43.6.243

50. Y.V.R.K. Prasad, H.L. Gegel, S.M. Doraivelu, J.C. Malas, J.T. Morgan, K.A. Lark and D.R. Barker, Modeling of Dynamic Material Behavior in Hot Deformation: Forging of Ti-6242, Metall. Trans. A, 1984, 15(10), p 1883-1892. https://doi.org/10.1007/BF02664902

51. S.V.S.N. Murty, M.S. Sarma, and B.N. Rao, On the Evaluation of Efficiency Parameters in Processing Maps, Metall. Mater. Trans. A Phys. Metall. Mater. Sci., 1997, 28(7), p 1581-1582

52. M.A. Shaikh, M. Iqbal, M. Ahmad, J.I. Akhtar and K.A. Shoaib, Precipitation Study of Heat-Treated Incoloy 825 by Scanning Electron Microscopy, J. Mater. Sci. Lett., 1992, 11(14), p 1009-1011. https://d oi.org/10.1007/BF00729911

53. E.L. Raymond, Mechanisms of Sensitization and Stablization of Incoloy Nickel-Lron-Chromium Alloy 825, Corrosion, 1968, 68, p 180-188. https://doi.org/10.5006/0010-9312-24.6.180

54. E.L.Hibner, C.S.Tassen, and J.W. Skogsberg, "Effect of Alloy Nickel Content Vrs. Pren on the Selection of Austenitic Oil Country Tubular Goods for Sour Gas Service," Paper No. 98106, NACE-CORROSION, 1998

55. J. Rosenberg, P. Adderley, V. Hart, and J. Klöwer, "Development of an Improved Version of UNS N08825 with Higher Corrosion Resistance," Corrosion, 2016

56. Mitra Basirat, "Microstructural Evolution In As-Cast Alloys during Plastic Deformation.," (Stockholm, Sweden), Ph.D. Thesis, KTH Royal Institute of Technology, Stockholm, Sweden, 2013

57. M. Niikura, K. Takahashi and C. Ouchi, Microstructural Change of Austenite in Hot Working with a Very High Reduction, Trans Iron Steel Inst Japan, 1987, 27(6), p 485-491. https://doi.org/10.2355/isiji nternational1966.27.485

58. Herdiana, "Modelling Hot Deformation of Steels." Climate Change 2013 - The Physical Science Basis, J.G. Lenard, Ed., (Berlin, Heidelberg), Springer Berlin Heidelberg, 1989

59. H. Fazilatpanah, M.R. Jahangiri and A.R. Khodabandeh, Hot Deformation Behavior and Processing Maps of Iron-Nickel Based Superalloy, Materwiss. Werksttech., 2019, 50(11), p 1407-1417.

60. H. John and M. Sellars, Modelling Rolling Microstructure and Its Effects during Multipass Hot, Iron Steel Inst. Japan Int., 1992, 32, p 359-367.

61. D.W. Livesey and C.M. Sellars, Hot-Deformation Characteristics of Waspaloy, Mater. Sci. Technol. (United Kingdom), 1985, 1(2), p 136144.

62. M. Luton and C. Sellars, Dynamic Recrystallization in Nickel and Nickel-Iron Alloys during High Temperature Deformation, Acta Metall., 1969, 17(8), p 1033-1043. https://doi.org/10.1016/0001-6160 (69)90049-2

63. H. Mirzadeh, J.M. Cabrera and A. Najafizadeh, Constitutive Relationships for Hot Deformation of Austenite, Acta Mater., 2011, 59(16), p 6441-6448. https://doi.org/10.1016/j.actamat.2011.07.008

64. C.M. Sellars, Computer Modelling of Hot-Working Processes, Mater. Sci. Technol. (United Kingdom), 1985, 1(4), p 325-332. 
65. C.M. Sellars, The Kinetics of Softening Processes during Hot Working of Austenite, Czechoslov. J. Phys., 1985, 35(3), p 239-248. https://doi. org/10.1007/BF01605090

66. C.M. Sellars and W.J. McTegart, On the Mechanism of Hot Deformation, Acta Metall., 1966, 14(9), p 1136-1138. https://doi.org/10.1016/ 0001-6160(66)90207-0

67. H. Mirzadeh, A. Najafizadeh and M. Moazeny, Flow Curve Analysis of 17-4 PH Stainless Steel under Hot Compression Test, Metall. Mater. Trans. A, 2009, 40(12), p 2950-2958. https://doi.org/10.1007/s11661009-0029-5

68. J. Long Qu, Z. Nan Bi, J. Du. Hui, M. Qing Wang, Q. Zeng Wang and J. Zhang, Hot Deformation Behavior of Nickel-Based Superalloy GH4720Li, J. Iron Steel Res. Int, 2011, 18(10), p 59-65.

69. J. Wang, J. Dong, M. Zhang and X. Xie, Hot Working Characteristics of Nickel-Base Superalloy $740 \mathrm{H}$ during Compression, Mater. Sci. Eng. A, 2013, 566, p 61-70. https://doi.org/10.1016/j.msea.2012.12.077

70. R.R. Eleti, T. Bhattacharjee, L. Zhao, P.P. Bhattacharjee and N. Tsuji, Hot Deformation Behavior of CoCrFeMnNi FCC High Entropy Alloy, Mater. Chem. Phys., 2018, 210, p 176-186. https://doi.org/10.1016/j. matchemphys.2017.06.062

71. K.A. Babu, S. Mandal, A. Kumar, C.N. Athreya, B. de Boer and V.S. Sarma, Characterization of Hot Deformation Behavior of Alloy 617 through Kinetic Analysis, Dynamic Material Modeling and Microstructural Studies, Mater. Sci. Eng. A, 2016, 664, p 177-187. https://doi.org/ 10.1016/j.msea.2016.04.004

72. A. Anitha Lakshmi, C. Srinivasa Rao, J. Gangadhar, C. Srinivasu and S.K. Singh, Review of Processing Maps and Development of Qualitative Processing Maps, Mater. Today Proc., 2017, 4(2), p 946956.

73. A. Thomas, M. El-Wahabi, J.M. Cabrera and J.M. Prado, High Temperature Deformation of Inconel 718, J. Mater. Process. Technol., 2006, 177(1-3), p 469-472.

74. A. Nowotnik, Effect of High Temperature Deformation on the Structure of Ni Based Superalloy, J. Achiev. Mater. Manuf. Eng., 2008, 27(2), p 115-122.

75. R.H. Zhang, Z.H. Wang, Z.P. Shi, B. Wang and W.T. Fu, Dynamic and Postdeformation Recrystallization of Nuclear-Grade 316LN Stainless Steel, Strength Mater., 2015, 47(1), p 94-99. https://doi.org/10.1007/ s11223-015-9633-3

76. M.S. Lewandowski, V. Sahai, R.C. Wilcox, C.A. Matlock and R.A Overfelt, High Temperature Deformation of Inconel 718 Castings, Superalloys, 1994, 718, p 625-706.

77. I. Sen, R.S. Kottada and U. Ramamurty, High Temperature Deformation Processing Maps for Boron Modified Ti-6Al-4V Alloys, Mater. Sci. Eng. A, 2010, 527(23), p 6157-6165.

78. A. Amiri, M.H. Sadeghi and G.R. Ebrahimi, Characterization of Hot Deformation Behavior of AMS 5708 Nickel-Based Superalloy Using Processing Map, J. Mater. Eng. Perform., 2013, 22(12), p 3940-3945.

79. M. Al-Saadi, F. Sandberg, A. Kasarav, S. Jonsson and P. Jönsson, Microstructure Characterisation in Alloy 825, Procedia Manuf., 2018, 15, p 1626-1634. https://doi.org/10.1016/j.promfg.2018.07.294

80. H.T. Jeong, H.K. Park and W.J. Kim, Hot Deformation Behavior and Processing Map of a Sn0.5CoCrFeMnNi High Entropy Alloy with Dual Phases, Mater Sci Eng A, 2021, 801, p 140394.

81. S. Mandal, A.K. Bhaduri and V. Subramanya Sarma, A Study on Microstructural Evolution and Dynamic Recrystallization during Isothermal Deformation of a Ti-Modified Austenitic Stainless Steel, Metall. Mater. Trans. A Phys. Metall. Mater. Sci., 2011, 42(4), p 1062 1072.
82. Q. Zeng, B. Luan, Y. Wang, X. Zhang, R. Liu, K.L. Murty and Q. Liu, Effect of Initial Orientation on Dynamic Recrystallization of a Zirconium Alloy during Hot Deformation, Mater. Charact., 2018, 145, p 444-453. https://doi.org/10.1016/j.matchar.2018.09.008

83. X.Q. Yin, C.H. Park, Y.F. Li, W.J. Ye, Y.T. Zuo, S.W. Lee, J.T. Yeom and X.J. Mi, Mechanism of Continuous Dynamic Recrystallization in a 50Ti-47Ni-3Fe Shape Memory Alloy during Hot Compressive Deformation, J. Alloys Compd., 2017, 693, p 426-431. https://doi.org/10. 1016/j.jallcom.2016.09.228

84. A.J. Schwartz, M. Kumar, B.L. Adams, and D.P. Field, "Electron Backscatter Diffraction in Materials Science," Materials Science and Engineering A, A.J. Schwartz, M. Kumar, B.L. Adams, and D.P. Field, Eds. Springer US: (Boston, MA) 2009 https://doi.org/10.1007/978-0387-88136-2

85. T.H. Lee, Y.J. Lee, S.H. Joo, H.H. Nersisyan, K.T. Park and J.H. Lee, Intergranular M23C6 Carbide Precipitation Behavior and Its Effect on Mechanical Properties of Inconel 690 Tubes, Metall. Mater. Trans. A Phys. Metall. Mater. Sci., 2015, 46(9), p 4020-4026.

86. C.D. Barrett, A. Imandoust, A.L. Oppedal, K. Inal, M.A. Tschopp and H. El. Kadiri, Effect of Grain Boundaries on Texture Formation during Dynamic Recrystallization of Magnesium Alloys, Acta Mater., 2017, 128, p 270-283. https://doi.org/10.1016/j.actamat.2017.01.063

87. S. Mitsche, P. Poelt and C. Sommitsch, Recrystallization Behaviour of the Nickel-Based Alloy 80 a during Hot Forming, J. Microsc., 2007, 227(3), p 267-274.

88. M. Al-Saadi, F. Sandberg, C. Hulme-Smith, A. Karasev and P.G. Jönsson, A Study of the Static Recrystallization Behaviour of Cast Alloy 825 after Hot-Compressions, J. Phys. Conf. Ser., 2019, 1270, p 012023. https://doi.org/10.1088/1742-6596/1270/1/012023

89. K. Huang and R.E. Logé, A Review of Dynamic Recrystallization Phenomena in Metallic Materials, Mater. Des., 2016, 111, p 548-574. h ttps://doi.org/10.1016/j.matdes.2016.09.012

90. M.F.A.H.J. Frost, Deformation-Mechanism Maps. The Plasticity and Creep of Metals and Ceramics, Pergamon Press, Oxford, 1982

91. L. Yang, Z. Geng, M. Zhang and J. Dong, Study on Hot Deformation Behavior and Numerical Simulation for Hot Extrusion Process of Corrosion Resistant 825 Alloy, Procedia Eng., 2011, 2012(27), p 9971007. https://doi.org/10.1016/j.proeng.2011.12.547

92. K. Takahashi, C. Ouchi and M. Niikura, Microstructural Change of Austenite in Hot Working with a Very High Reduction, Trans. ISIJ , 1987, 27(6), p 485-491.

93. M. Aghaie-Khafri and F. Adhami, Hot Deformation of 15-5 PH Stainless Steel, Mater. Sci. Eng. A, 2010, 527(4-5), p 1052-1057. h ttps://doi.org/10.1016/j.msea.2009.09.032

94. A.A. Guimaraes and J.J. Jonas, Recrystallization and Aging Effects Associated with the High Temperature Deformation of Waspaloy and Inconel 718, Metall. Trans. A, 1981, 12(9), p 1655-1666. https://doi. org/10.1007/BF02643571

95. S.P. Coryell, K.O. Findley, M.C. Mataya and E. Brown, Evolution of Microstructure and Texture during Hot Compression of a Ni-Fe- $\mathrm{Cr}$ Superalloy, Metall. Mater. Trans. A Phys. Metall. Mater. Sci., 2012, 43(2), p 633-649.

Publisher's Note Springer Nature remains neutral with regard to jurisdictional claims in published maps and institutional affiliations. 